\title{
Allowance for capacity adequacy criterion in optimizing the prospective structure of electric power system
}

\author{
Nikolay Belyaev ${ }^{1, *}$, Andrey Egorov ${ }^{1}$, Nikolay Korovkin ${ }^{2}$ and Vladimir Chudny ${ }^{2}$ \\ ${ }^{1}$ Russian Energy Agency Ministry of Energy of the Russian Federation, Russia \\ ${ }^{2}$ Peter the Great St.Petersburg Polytechnic University, Russia
}

\begin{abstract}
This paper considers the optimization procedure of electric power system prospective structure with account made for two criteria: economic value (minimization of specific reduced energy costs for customers) and capacity adequacy (minimization of capacity shortage probability). The proposed procedure is based on genetic algorithm application. The results of procedure evaluation have been considered by the example of optimization of the structure of generating capacities within concentrated power system.
\end{abstract}

\section{Introduction}

The standard problem statement of planning electric power systems (EPS) reduces to cost-minimizing procedure in relation to total reduced costs 3 connected with electric power supply to consumers $[1,2]$ :

$$
\begin{aligned}
& 3(\mathbf{x})=\sum_{t}\left(3_{t}^{\mathrm{K}}(\mathbf{x})+3_{t}^{\mathrm{O}}(\mathbf{x})\right) \cdot(1+d)^{-t} \underset{\mathbf{x}}{\longrightarrow} \min , \\
& \mathbf{x} \in R,
\end{aligned}
$$

where $3_{t}^{\mathrm{K}}, 3_{t}^{\mathrm{O}}$ - capital and operational costs per year $t$ respectively, $d$-discount rate. Variables $\mathbf{x}$ in problem (1) are major engineering solutions of planning electrical generation, transmission and distribution systems that determine their cost-based value and structure. The range of limitations $R$ is specified by EPS reliability and security requirements influencing the choice of certain engineering solutions or their combinations. Such limitations include, among others, the EPS adequacy requirements which are given as regulated value of capacity adequacy index (CAI) or respective capacity $\operatorname{margin}[3,4]$.

Such an approach of taking into account the capacity adequacy requirements has some disadvantages because it needs to be feasibly studied in terms of mentioned regulated CAI value. This kind of study is made difficult due to the absence of appropriate assessment of damages arising from capacity shortage and to complicated way of its acquisition defined by the variety of EPS customers' composition and their modes of operation. Moreover, known procedures of CAI regulated value justification [5] are based on the assumption of linear relation existing between cost-based margin capacity and its value that reveals to be unfair bearing in mind a real structure of generating capacities in electric power systems.

So, this paper proposes a two-criterion problem statement of EPS planning providing for low costing with CAI minimization - probability $J_{\text {Д }}$ of capacity shortage in EPS:

$$
\begin{aligned}
& 3(\mathbf{x}) \longrightarrow \mathbf{x} \text { min, } \\
& J_{\text {д }}(\mathbf{x}) \stackrel{\mathrm{x}}{\longrightarrow} \min , \\
& \mathbf{x} \in R .
\end{aligned}
$$

\section{Source data, variables and constraints}

When planning EPS, engineering solutions should be examined after having been integrated in technologies [2] under types and performance-based indicators. The potential structure of these technologies is given in Table 1. Technologies of generation development $(G)$ cover power station units and power generation plants of various types of different unit capacity. Technologies covering the development of electrical networks are as follows: construction of new power transmission lines of various voltage classes as well as means of reactive power compensation making possible to expand their capacity. Each technology should be provided with performance indicators and reliability data so as to ensure the calculation of target functions (2). Parameters related to the demand of power supply in EPS must be given as source data: forecast power consumption, peak electrical demands and electricity load curves, nonconforming load indicators with details for every node of electric power system.

Variables in the problem are discrete values $x_{k, i} \in \mathbf{x}$ that correspond to the number of technology $k$ measures to be implemented in node $i$ which is understood as a part of power system (zone) where there is no limitation for power transmission [6].

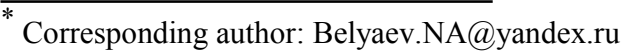


Table 1. Structure of technologies at EPS planning.

\begin{tabular}{|c|c|c|c|c|c|}
\hline Type & Name & $\begin{array}{c}\text { Avai- } \\
\text { lable } \\
\text { (maxi- } \\
\text { mum) } \\
\text { capacity, } \\
\text { MW }\end{array}$ & $\begin{array}{l}\text { Tech- } \\
\text { nolo- } \\
\text { gical } \\
\text { mini- } \\
\text { mum, } \\
\text { MW }\end{array}$ & $\begin{array}{c}\text { Specific } \\
\text { capital } \\
\text { costs, th. } \\
\text { Rub } / \mathrm{kW} \\
(\mathrm{mln} \\
\text { Rub } / \mathrm{km})\end{array}$ & $\begin{array}{c}\text { Specific } \\
\text { opera- } \\
\text { tional } \\
\text { costs } \\
\mathrm{Rub} / \\
\mathrm{kW} \cdot \mathrm{h}\end{array}$ \\
\hline \multicolumn{6}{|c|}{ Generation } \\
\hline TPP & ST-50 & 50 & 40 & 55 & 1,17 \\
\hline TPP & ST-100 & 100 & 80 & 50 & 1,11 \\
\hline CTPP & CTST-50 & 50 & 25 & 50 & 1,17 \\
\hline CTPP & CTST-100 & 100 & 50 & 45 & 1,11 \\
\hline СТPP & CTST-200 & 200 & 100 & 40 & 1,08 \\
\hline CTPP & CTST-300 & 300 & 150 & 37 & 1,05 \\
\hline CTPP & CTST-500 & 500 & 250 & 35 & 1,03 \\
\hline СТPP & CTST-600 & 600 & 360 & 50 & 0,70 \\
\hline СТPP & CTST-800 & 800 & 400 & 34 & 1,00 \\
\hline CTPP & CCP-150 & 150 & 60 & 60 & 0,77 \\
\hline СТРP & CCP-450 & 450 & 180 & 50 & 0,73 \\
\hline CTPP & CCP-800 & 800 & 240 & 40 & 0,69 \\
\hline СТPP & GT-50 & 50 & 0 & 65 & 1,24 \\
\hline CTPP & GT-100 & 100 & 0 & 60 & 1,17 \\
\hline HPP & $\begin{array}{c}\text { Hydraulic } \\
\text { unit-100 }\end{array}$ & 100 & 15 & 145 & - \\
\hline HPP & $\begin{array}{c}\text { Hydraulic } \\
\text { unit-300 }\end{array}$ & 300 & 30 & 120 & - \\
\hline NPP & $\begin{array}{c}\text { LWGR- } \\
1200\end{array}$ & 1200 & 1200 & 110 & - \\
\hline WG & WG-50 & $*$ & $*$ & 150 & - \\
\hline \multicolumn{6}{|c|}{ Network } \\
\hline TL & $220 \mathrm{kV}$ & 249 & - & 12 & - \\
\hline $\mathrm{TL}$ & $330 \mathrm{kV}$ & 748 & - & 13 & - \\
\hline $\mathrm{TL}$ & $500 \mathrm{kV}$ & 1698 & - & 19 & - \\
\hline CSR & $\begin{array}{c}\text { per 1 } \\
\text { kVAr }\end{array}$ & - & - & 3 & - \\
\hline $\mathrm{CB}$ & $\begin{array}{l}\text { per } 1 \\
\text { kVAr }\end{array}$ & - & - & 0,4 & - \\
\hline
\end{tabular}

* to be specified as probability distribution series [7]

Range $R$ is described by different limitations:

maximum or minimum possible (with account made for existing EPS structure and solutions adopted for implementation) number $\left(\underline{x}_{k, i}, \bar{x}_{k, i}\right)$ of measures for each technology:

$$
\underline{x}_{k, i} \leq x_{k, i} \leq \bar{x}_{k, i},
$$

total volume of generating capacities required as a value of maximum electrical load $N_{\max }$ :

$$
\sum_{i} \sum_{k} P_{k} x_{k, i} \geq N_{\max }, \quad k \in G,
$$

where $P_{k}-$ available unit capacity of generating equipment under technology $k$,

technical constraints of total capacity $\left(\underline{P}_{k, i}, \bar{P}_{k, i}\right)$ of certain types of power plants: as per technological minimum, fuel supplies, required volume of thermal energy supply (for TPP) etc.:

$$
\underline{P}_{k, i} \leq P_{k} x_{k, i} \leq \bar{P}_{k, i} \text {. }
$$

\section{Solution}

To solve the problem (2) with account made for constraints (3) - (5) while considering its discreteness and availability of two criteria a genetic algorithm is proposed for application whose principal provisions in terms of branch problems are given in [8]. The calculation of target functions on each algorithm step is carried out by applying Monte-Carlo technique in the following way:

1. For each formed version of solution multiple random states of EPS are examined with account made for EPS maintenance outages and emergency repairs, regular or irregular load changes, available capacity changes of seasonal and stochastic nature on the basis of indicators given as source data. The following should be specified for each described state: working capacity $P_{\mathrm{P} i}$ of power plants in nodes, load $N_{i}$ for customers in nodes, transmission capacity $Z_{i, j}$ of connections between nodes.

2 . For every random state the problem of capacity shortage minimization $D_{i}$ is to be solved:

$$
\begin{aligned}
& \sum_{i} D_{i} \underset{P_{\mathrm{H} i}}{\longrightarrow} \min \\
& \sum_{i}\left(P_{\mathrm{H} i}-n_{i}\right)=0, \\
& \forall i: D_{i}=N_{i}-n_{i} \geq 0, \\
& \quad P_{\mathrm{H} i} \leq P_{\mathrm{P} i}, \\
& \forall i, j: \sum_{m} k_{m}^{i, j}\left(P_{\mathrm{H} m}-n_{m}\right) \leq Z_{i, j},
\end{aligned}
$$

where $P_{\mathrm{H} i}$ and $n_{i}$ - respectively actual loads of power plants and customers in nodes, $k_{m}^{i, j}$ - linear dependency factor of power flow between nodes $i, j$ in relation to node capacity $m$ (mains factor). The procedure of mains factor calculation is given in [9].

3 . To get values $n_{i}$ by results of solution (6) the problem of operational costs minimization $3^{\mathrm{O}}$ is to be solved:

$$
\begin{aligned}
& 3^{\mathrm{O}} \underset{P_{\mathrm{H} i}}{\longrightarrow} \min \\
& \sum_{i}\left(P_{\mathrm{H} i}-n_{i}\right)=0, \\
& \forall i: P_{\mathrm{H} i} \leq P_{\mathrm{P} i}, \\
& 3^{\mathrm{O}}=\sum_{i} \sum_{k} P_{\mathrm{H} k, i} 3_{k}^{\mathrm{o}}, \\
& \forall i, j: \sum_{m} k_{m}^{i, j}\left(P_{\mathrm{H} m}-n_{m}\right) \leq Z_{i, j},
\end{aligned}
$$

where $3_{k}^{0}-$ specific operational costs of technology $k$ $(k \in G)$.

4. Following the results of solution of (6) and (7) for random sets the values of target functions (2) of a given solution option are defined. The probability of capacity shortage is defined as a relative number of states with capacity shortage obtained upon solution of (6), the value of total costs is according to (1) with account of average value $3^{\mathrm{O}}$, got upon solution results of (7).

Based on the results of problem (2) solution the variety of Pareto optimal solutions is specified, its analysis provides for the definition of the influence of CAI regulated value change on the value of costs required for its obtaining and for selection of the most appropriate option of EPS planning.

It should be noted that to get a feasible accuracy of target function calculations (2) the number of random states for each alternate solution must make $\sim 10^{6}$. In 
such a case to ensure the algorithm convergence at specific number of variables of $\sim 20$ the number of single generation should be at least $10^{3}$. Thus, when the number of generations is $\sim 10^{2}$, one must estimate $\sim 10^{11}$ random EPS states by solving (6) and (7) in order to get the solution of studied problem.

\section{Evaluation}

Calculations have been performed for a single-node EPS. Maximum load of EPS makes 12,87 GW, the load curve irregularity factor being of 0,77 and the load factor - of 0,92 . To carry out calculations there has been accepted the structure of technologies according to data of Table 1 while the equipment reliability indicators are in line with data [10]. The results are shown on Fig. 1.

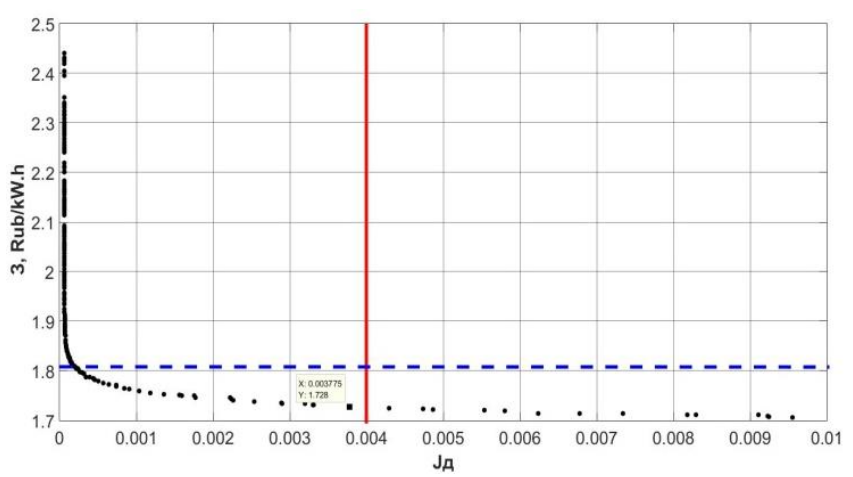

Fig. 1. Calculation results.

On Fig. 1 the values of target functions (2) are plotted on axes: on horizontal line - probability of capacity shortage, on vertical line - working cost of electric energy compatible with accumulated total costs. Points mark the results. The total number of obtained solutions is equal to 375 .

During Soviet time the regulated value of CAI has been justified and until now it is applied at the level of $0,996[1,5]$, that is in line with $J_{\text {Д }}=0,004$. Thus, when using this rate one should choose the solution marked on Fig. 1, in this case the electricity cost will make 1,73 Rub./kWh. However this option does not seem to be optimal if other solutions are examined. For example, an insignificant price increase within $1 \mathrm{cop} . / \mathrm{kWh}$ allows reducing $J_{\text {Д }}$ to the level of 0,00226 . Moreover, it should be noted that from cause-and-effect view under circumstances when the operating conditions of EPS through the long run are uncertain, the parameter setting error for technologies applied in problem as source data, cost parameters, first of all, may reach up to 5 per cent and more that significantly affects the accuracy of cost assessment. In this case the price increase by 5 per cent as compared to the solution marked on Fig. 1 (up to 1,81 Rub./kWh, shown by horizontal dot lines) allows reducing $J_{\text {Д }}$ up to 0,00016 , i.e. more than by an order of magnitude.

Further reduction of $J_{\text {д }}$ may appear to be costineffective as costs progress at a far quicker rate and an insignificant reduction of $J_{\text {д }}$ results in price hikes. At a price of $1,97 \mathrm{Rub} . / \mathrm{kW} \cdot \mathrm{h}$ the limit value of $J_{\text {Д }} \sim 6,3 \cdot 10^{-5}$, is reached, in practice it is insensitive to price increase.
The range of installed capacity variation upon got solutions was within $14,95 \mathrm{GW}-22,15 \mathrm{GW}$ that is in line with the margin capacity value from $16,2 \%$ to $72,1 \%$ of EPS maximum load. For the solution marked on Fig. 1 which is in conformity with regulated CAI, the capacity margin was $19,7 \%$. For the solution with the price of $1,81 \mathrm{Rub} . / \mathrm{kW}$ and $J_{\text {Д }}=0,00016$ the capacity margin is equal to $29,8 \%$.

\section{Conclusion}

In comparison with standard problem statement of EPS planning (1) the solution of proposed problem (2) allows not only taking into account regulated requirements as to EPS capacity adequacy but selecting an optimal level of capacity adequacy on the basis of evaluation of costs increase incurred to its provision with due account made for a specific EPS and potential engineering solutions. In this case based on performed calculations a better CAI improvement in relation to regulated level at insignificant cost increase within the range of source data setting accuracy.

It should be noted that there is the possibility to set the problem (2) by including therein additional criteria effective for EPS planning. Such criteria are minimization of environmental impacts (minimization of fuel plant emis-sions), ensurance of energy security (minimization of installed capacity shortage in certain EPS nodes) etc.

\section{References}

1. I.M.Volkenau, A.N.Zeiliger, L.D.Khabachev, Economics of electric power system formation (Energiya, Moscow, 1981)

2. F.V.Veselov, T.V.Novikova, A.V.Fedosova, Fundamentals of electric power's economics: Guidelines (Gubkin Russian State University of Oil and Gaz, Moscow, 2016)

3. Yu.Ya.Chukreev, M.Yu.Chukreev, Models of evaluation of capacity adequacy indices when managing the development of electric power systems (Komi scientific centre, Syktyvkar, 2014)

4. D.V.Iakubovskii, D.S.Krupenev, D.A.Boyarkin, E3S Web of Conferences, 114, 03002 (2019)

5. D.S.Krupenev, L.M.Lebedeva, G.F.Kovalev, N.A.Belyaev, A.E.Egorov, R.E.Gromov, Energy policy, E 1, 33 (2018)

6. N.Belyaev, A.Egorov, N.Korovkin, V.Chudny, E3S Web of Conferences, 58, 01010 (2018)

7. D.Krupenev, E3S Web of Conferences, 58, 01012 (2018)

8. N.V.Korovkin, A.A.Potienko, Electricity, E 1, 2 (2002)

9. N.A.Belyaev, A.E.Egorov, N.V.Korovkin, V.S.Chudny, Electricity, E 5, 11 (2018)

10. V.A.Nepomniaschiy, Reliability of electrical power system equipment (Electroenergiya. Transmission and distribution, Moscow, 2013) 